\title{
Trading off efficiency and equity A Scandinavian puzzle?
}

\author{
Torben M. Andersen ${ }^{1}$
}

\begin{abstract}
One of the most fundamental trade-offs in economics is that between efficiency and equity. The performance of the Scandinavian countries with high incomes and low inequality in an international perspective creates a paradox in this context since these countries are also high tax countries. The Scandinavian experience seems to suggest that tax distortions are small, and the trade-off between efficiency and equity therefore is relatively flat. This paper argues that this does not necessarily imply that economic incentives do not matter, but rather that the standard distortionary effects of taxation may be countered by other effects. The particular effect considered here is the interaction between taxation and risk. It is shown that the implication of taxation for labour supply depends critically on whether the return to work is risky since taxes provide implicit insurance of income risk. The wedge implied by income taxation depends negatively on risk, implying that tax distortions are smaller when explicit account is taken of risk. As a consequence, labour supply may be rather insensitive to tax changes or may even be increasing in the tax rate. It is an implication that the trade-off between incentives and insurance, or equivalently efficiency and equity, may be rather flat or even non-monotone.
\end{abstract}

JEL: H20, J22, H80.

Keywords: Risk, taxation, labour supply, inequality, efficiency.

1 Torben M. Andersen is a Professor at the Department of Economics, University of Aarhus, and a research fellow at the CEPR, CESifo and IZA. The Paper was presented at the symposium in honour of Professor Gudmundur Magnusson, University of Iceland, Reykjavik, November 2007. 


\section{Introduction}

The effect of taxes on economic performance is one of the most recurrent and controversial issues in economic policy debates. Are high tax burdens - in particular high marginal tax rates - a significant barrier to economic efficiency? Standard theory teaches us that there is a trade-off between efficiency and equity; that is, redistribution running via taxation is costly since it distorts economic incentives, which in turn implies efficiency losses. It is an important policy question how steep this trade-off is, and whether there is always such a trade-off in policy design.

A very crude initial approach to clarifying this issue can be taken by considering the per capita income level as a measure of efficiency and the Gini-coefficient as a metric of inequality (or 100-Gini as a measure of equity). While there are numerous problems with data and their interpretation, a cross-plot of these data may give a first indication of the importance of such a trade-off. Figure 1 presents such data for high income OECD countries. In this cross-plot, Norway and Ireland may be considered outliers, ${ }^{2}$ and therefore the line inserted may be interpreted as giving the international frontier or best practice in the efficiency-equity space. This line suggests that there is a trade-off, but also that it is not very steep.

Figure 1. Income per capita vs. equality, selected OECD countries.

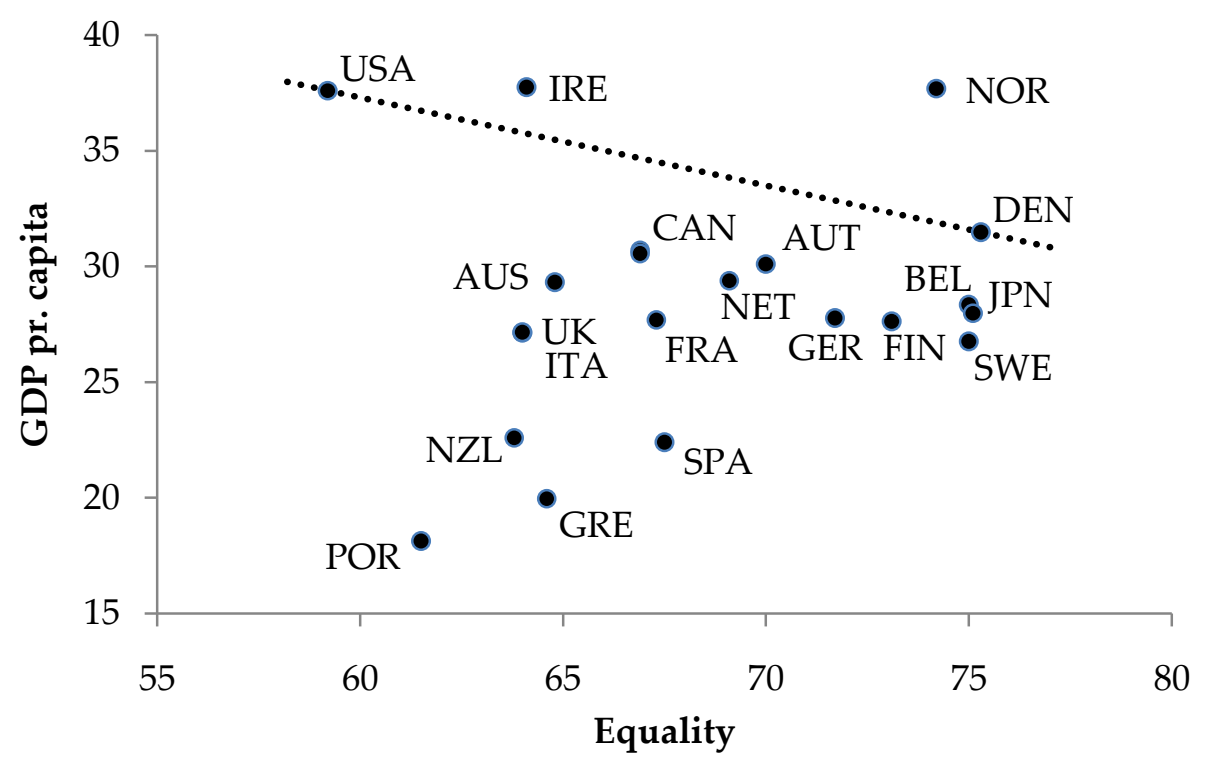

Note: GDP in PPP adjusted \$, and equality measured by the 100-Gini coefficient, both for 2006. Data from the Human Development Index.

It is particularly noteworthy that some countries - mostly Northern European/Scandinavian - score high in terms of equality without losing much in terms of average income. One may say that this is a Scandinavian puzzle to the extent that these countries have a large public sector and high tax burdens amounting to $50 \%$ of GDP. The cross-country comparison indicates either that tax

2 For Norway, GDP per capita is boosted by the petroleum sector accounting for about $1 / 4$ of value added. In Ireland, a large share of income goes to foreigners, and the discrepancy between GDP and GNI per capita is about $15 \%$ lower than GDP per capita. Accounting for these factors would move Norway and Ireland close to the line depicted in the figure. 
distortions cannot be that important or that there are some counterweighting effects. Clarification of these questions is particularly important to Scandinavian countries, who have built welfare states based on a large public sector and thus high tax rates.

Underlying the perception that the trade-off between efficiency and equity is steep is the presumption that tax wedges distort labour markets. Hence, the higher the tax wedges, the lower the employment level, which in turn implies greater efficiency losses. However, the consensus finding across numerous empirical studies of labour supply responses is that the response to taxes is rather low (see e.g. Blundell and MaCurdy (1999) for a survey and references). Figure 2 illustrates this point, using cross-section data on the tax burden and the employment rate across OECD countries. It is seen that a high tax burden is not associated with lower employment as is also exemplified by the Scandinavian countries having both high tax burdens and high employment rates. Considering working hours as in figure 3 , there is a negative relationship, but again it is not very steep. ${ }^{3}$

Figure 2. Tax burden and employment rate-OECD countries.

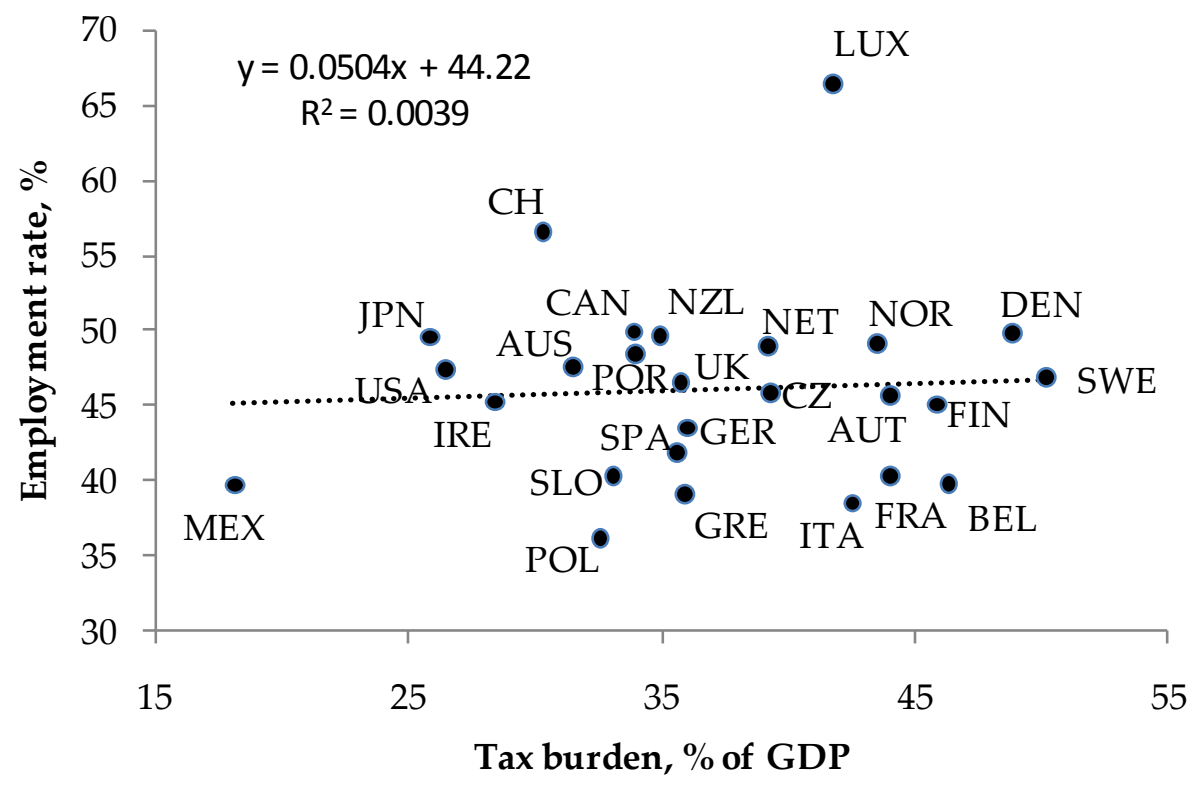

Note: Data applies to 2004, from OECD factbook.

3 Estimating a log relation of working hours and tax burdens across this sample implies an elasticity equal to -0.25 . 
Figure 3. Tax burden and working hours - OECD countries.

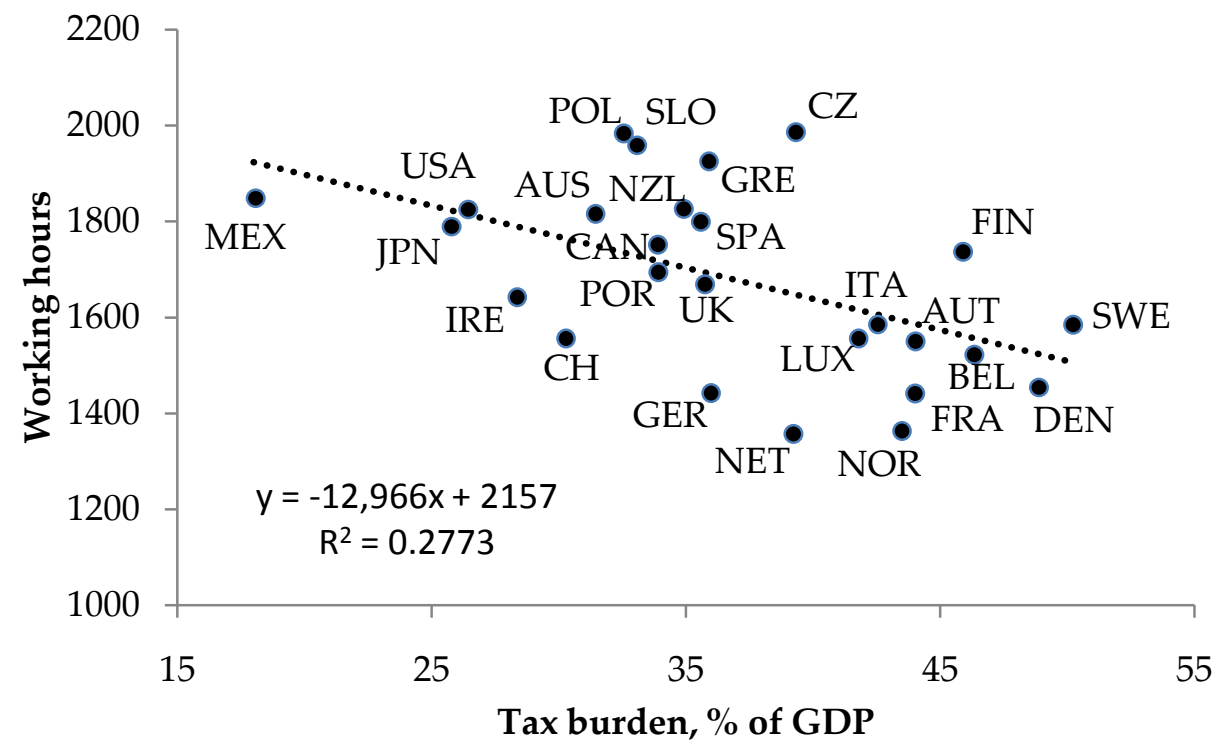

Note: Data applies to 2004, and is adapted from OECD factbook.

A recent wave in the debate on the role of taxes for economic performance has been fuelled by the controversial paper by Prescott (2004), arguing that differences in labour supply (measured as total hours supplied relative to population) between the US and some larger European countries can be accounted for by the difference in tax rates. Hence, by implication, if these European countries were to reduce taxes to the US level, the labour input would be about the same on a per capita basis (see also Ohanion, Raffo and Rogerson (2006)). In subsequent debates, this claim has been criticized for assuming an implausibly large labour supply elasticity way above any available empirical micro evidence. Other arguments have been that Europeans have a stronger preference for leisure, that the welfare state via generous benefit levels lowers labour supply and the role of imperfect competition (unions), see e.g. Alesina, Glaeser and Sacerdote (2005), Lundqvist and Sargent (2007), and Gordon (2006). However, all of these mechanisms do not explain the Scandinavian puzzle, but rather strengthen it, since they tend to go in the direction of implying that labour supply should be even lower in high tax countries like the Scandinavian. As is well-known, the overall labour force participation rate is high in the Scandinavian countries, and hence these high tax countries are somehow outliers in the tax-labour supply chart. The issue thus remains how is it possible for Scandinavian countries with larger public sectors and high tax burdens to maintain a high employment rate and a high per capita income?

At first sight one may conclude from these facts that economic incentives, in particular tax wedges, do not matter much. This conclusion is premature since the above presentation of data does not control for various background variables that may interact with economic incentives. Hence, there are some mechanisms which may counterweight the implication of tax wedges. Such counterweighting effects may be grouped in four types of explanations. First, tax distortions cannot be seen independently of what taxes are financing (a point already made by Winston (1965)), and e.g. the distortionary effects of taxes financing day care are different from taxes financing e.g. early retirement. Second, the distortions of labour supply decisions (in 
particular participation) depend not only on taxes and the generosity of the social safety net but also on the conditions built into the welfare system at large. The Scandinavian model is an employment focussed model, and although the social safety net is generous, the system is not unconditional in the sense that it offers a demo-grant or basic income. The system is very conditional and focussed on ensuring that individuals are active in the labour market (see e.g. Andersen and Pedersen (2008)). Thirdly, the institutional structure of labour markets in particular may matter. With highly centralized labour markets, the effects of taxes for e.g. working hours are different than in a decentralized market since central negotiators will internalize the government budget constraint. Finally, tax distortions may depend critically on other factors, in particular risk. It is beyond the scope of this paper to discuss all these mechanisms in detail, and the following focuses on exploring the role of taxation under risk.

The paper is organized as follows. First, the basic argument that a taxation system also implies an implicit insurance arrangement and is related to the problem of how taxes affect labour supply decisions is explained in section 2 . The implications of this mechanism are explored in section 3, which focuses on how taxes and risk interact in the determination of labour supply. The implications of this mechanism for the efficiency-equity trade-off are explored in section 4, and section 5 offers a few concluding remarks.

\section{Taxation as Implicit Insurance}

The effects of taxation in a deterministic setting are well known, and the specificities of tax wedges and labour supply are standard and included in all micro textbooks. However, the fact that taxation also has an insurance effect is less well known, although it arises from the fundamental reason that tax payment is conditional on say income, and such state-contingencies are the basic principle of insurance. This insight has been known for many years, and it is known in the literature as the Domar-Musgrave effect (Domar and Musgrave, 1944), building on the basic insight that an income tax not only affects expected return but also the variance of the disposable income if income is stochastic. This effect is lucidly summarized in the statement

"...because of the partnership of the government in risk-taking and the assumption of risk aversion..." (Magnusson, 1969, p. 223). ${ }^{4}$

A growing literature is building on this insight and is taking it further by noting that such contingencies arise not only in taxation but in many welfare arrangements, implying that they should not only be considered from a traditional perspective of redistribution but also from an insurance perspective (see e.g. Varian (1980), Eaton and Rosen (1980), Sinn (1995), Barr (2001), and Andersen and Dogonowski (2002)).

In the following we consider the effects of income taxation and the insurance it may provide in a basic setting focussing on a standard tax-transfer scheme. Such a scheme implies that there is a lump-sum transfer to all individuals and it is financed by a

4 Magnusson (1969) analysed a tax-transfer scheme like the one analysed in this paper, but he considered the implication for the factor decisions of firms. 
proportional tax on income. Such schemes have been widely studied in the literature since the seminal paper by Mirrless (1971). Mirrless (1971) considered such a scheme as a redistributive device in a setting with agents possessing different abilities and a government wanting to redistribute but facing the constraint that it can not observe individual abilities. In this setting a trade-off arises between the equity gains obtained by redistributing and the efficiency loss implied by the income tax. The following considers basically the same problem but focuses on risk as the source of income differences rather than abilities. Clearly, many factors can account for inequality, ${ }^{5}$ and hence the point here is not to take a stand on the relative importance of these factors but to explore the implications of the role of risk.

\subsection{Risk and a Tax-Transfer Scheme}

Consider an economy where an infinity of individuals decide on working time/effort, $h$, given a total time endowment, $n$ (i.e. leisure is $n-h$ ). The real wage earned is given by, $\omega$, and it is stochastic with mean $E(\omega)$ and standard deviation $S(\omega)$. Gross market income is thus $h \omega$ and subject to risk. Disposable income, and thus consumption (static case), is given by

$$
I=[1-\tau] h \omega+T
$$

where the tax is a proportional income tax and $T$ a lump-sum transfer to all agents. The net taxes paid are thus $\tau h \omega-T$. Considering the mean income and its standard deviation, we have

$$
\begin{aligned}
& E(I)=[1-\tau] h E(\omega)+T \\
& S(I)=[1-\tau] h S(\omega)
\end{aligned}
$$

Hence, it follows immediately that a higher tax rate reduces the expected return to work, but also that it lowers risk. Hence, it is not obvious how taxation would affect the labour supply decision taken by the individual.

Another way to see the implied insurance is that the government budget balance reads (in symmetric equilibrium where all individuals have chosen the same working hours)

$$
T=\tau h E(\omega)
$$

Note that the law of large numbers insures that the average income equals the expected income in the economy. The insurance mechanism is now easily seen by using the government budget constraint in the expression for the individual disposable income yielding 6

$$
I=h \omega+\tau h[E(\omega)-\omega]
$$

Hence, we have

5 At a general level, they may be grouped into characteristics (abilities, preferences etc.), choices (effort, education etc.) and risk (exogenous influences).

6 Note that this internalizes the budget constraint. The tax wedge arises because individuals do not internalize the government budget constraint in their decisions. 


$$
\begin{array}{rll} 
& >0 & \text { for } \omega<E(w) \\
\tau h[E(\omega)-\omega] & =0 & \text { for } \omega=E(w) \\
& <0 & \text { for } \omega>E(w)
\end{array}
$$

implying that there is a net-transfer from those being lucky (here: those having a wage rate above the mean) to those being unlucky (here: those having a wage rate below the mean). Hence, ex-post there is redistribution from high to low income individuals, but ex-ante this scheme serves an insurance function. Obviously, the higher the tax rate, the lower the risk. In the limit for a tax rate equal to one, all risk is eliminated from individual income. This would imply "full" insurance. However, this situation will not be optimal since absence of risk will also remove the incentive for individuals to work; that is, social or implicit insurance also has a moral hazard problem.

The above also brings out that a tax-transfer scheme releases no income effect (all tax revenue is handed back as lump sum transfers), and hence it focuses on the substitution effect potentially biasing the results in terms of allowing the maximal role of tax distortions.

\subsection{Labour Supply under Risk}

One reason why the implications of risk for taxation have not been much researched is probably that comparative static analyses of decision making under risk often get rather complicated and inconclusive. However, Meyer (1987) and Sinn (1995) have pointed out that many decision problems under risk satisfy the conditions, allowing expected utility to be written as an indirect utility function specified over the mean and standard deviation of a real income or utility measure. The crucial assumption is, loosely speaking, that the stochastic variable enters multiplicatively, which is clearly the case for labour supply under a stochastic wage since income is the product of the (stochastic) wage and working hours. Note that in this case no restrictions have to be made on the underlying distribution of stochastic variables (e.g. normal distribution) or the utility function (e.g. quadratic) to focus on the two moments, the mean and the standard deviation.

Define utility to depend on

$$
\begin{aligned}
y & =c-d(h) \\
& =[1-\tau] h \omega+T-d(h)
\end{aligned}
$$

where $c$ is consumption, and $d(h)$ the disutility from working $\left(d^{\prime}>0, d^{\prime \prime}>0\right)$. It follows that the mean and standard deviation of the utility metric are given as

$$
\begin{aligned}
& \mu \equiv E(y)=[1-\tau] h E(\omega)+T-d(h) \\
& \sigma \equiv S(y)=[1-\tau] h S(\omega)
\end{aligned}
$$

Since the utility is multiplicative in the stochastic variable, it follows that expected utility can be written (see Meyer (1987)) as a function of the mean and standard deviation of the utility metric, i.e.

$$
V(\mu, \sigma) ; V_{\mu}>0, V_{\sigma}<0
$$

7 The model presented here builds on Andersen (2008) to whom reference is made for further details and derivations of results. 
Note that the rate at which the individual for given expected utility is willing to substitute between the mean $(\mu)$ and risk $(\sigma)$ is given as

$$
\left.i(\mu, \sigma) \equiv \frac{\partial \mu}{\partial \sigma}\right|_{v}=-\frac{V_{\sigma}(\mu, \sigma)}{V_{\mu}(\mu, \sigma)}
$$

i.e. it measures the increase in the mean utility the agent requires to accept more risk for expected utility to remain unchanged. In the following, it is assumed that the compensation needed for agents to accept more risk is increasing in risk (i.e. $\left.\frac{\partial i(\mu, \sigma)}{\partial \sigma}>0\right)$.

Note all agents are ex-ante identical; that is, before the realisation of the shock $(\omega)$ is known, there are no differences between agents. Ex post subject to the realization of the shock there are differences. For given labour supply, some have low income due to a low realization of the state variable and some have a high income due to a high realization. The distribution function for the shock variable $(\omega)$ thus has the interpretation as the density function for individuals (i.e. they face risk concerning the future state of nature), while for society this is a frequency distribution given the inequality among agents. Note that labour supply is chosen before the realization of the state of nature is known; that is, agents make decisions under uncertainty. Moreover, the assumption of an infinite number of agents (the law of large numbers) is crucial. We can thus talk about risk and inequality interchangeably. The interesting aspect is that the outcome - here income - depends both on effort and risk, and the analysis here considers the interaction between the two given a public redistribution scheme involving insurance.

\subsection{Optimal Labour Supply}

We can now proceed to analyse the optimal individual labour supply and the possible distortions caused by the tax-transfer scheme. We start by characterizing optimal individual labour supply, and turn next to distortions.

The decentralized labour supply is characterized by

$$
i\left(\mu^{d}, \sigma^{d}\right)=\frac{[1-\tau] E(\omega)-d^{\prime}\left(h^{d}\right)}{[1-\tau] S(\omega)}
$$

where the superscript $d$ refers to the decentralized labour supply choice The condition says that the marginal rate at which the individual is willing to substitute the mean and risk (the LHS of the expression) equals the scope for shifting between the mean and risk by deciding on labour supply (the RHS of the expression). The optimal individual labour supply decision can be written in terms of an implicit function (for details see Andersen (2008))

$$
\begin{aligned}
& \qquad h=h(E(\omega), S(\omega), \tau) \\
& \text { where } \frac{\partial h}{\partial E(\omega)} \leq 0, \quad \frac{\partial h}{\partial \tau} \leq 0, \quad \frac{\partial h}{\partial S(\omega)} \leq 0 .
\end{aligned}
$$

The fact that the tax rate has an ambiguous effect on labour supply reflects that a higher tax releases both a negative incentive effect (reducing expected return from labour supply) and a positive insurance effect lowering the risk faced by individuals. Hence, depending on whether the incentive or the insurance effect dominates, an increase in the tax rate may decrease or increase labour supply. Specifically, we have 


$$
\operatorname{sign} \frac{\partial h}{\partial \tau} \leq 0 \text { for } S(\theta) \leq \tilde{S}(\theta)
$$

The intuition is that if risk is low $(S(\theta)<\tilde{S}(\theta))$, the insurance effect is less important and the incentive effect dominates; i.e. higher taxes reduce labour supply, and vice versa if risk is sufficiently high $(S(\theta)>\tilde{S}(\theta))$.

To evaluate how individual labour supply decisions are affected by the tax-transfer scheme, it is useful to make a comparison with the labour supply choice that the social planner will make for a given tax-transfer scheme. This decision problem implies a first order condition

$$
i\left(\mu^{s}, \sigma^{s}\right)=\frac{E(\omega)-d^{\prime}\left(h^{s}\right)}{[1-\tau] S(\omega)}
$$

where the superscript $s$ refers to the social planner's solution.

It is seen that the marginal rate of substitution between expected return and risk faced by the social planner $\left(\left.\frac{\partial \mu}{\partial \sigma}\right|^{s}=i\left(\mu^{s}, \sigma^{s}\right)\right)$ is larger than the marginal rate of substitution perceived by individual decision makers $\left(\left.\frac{\partial \mu}{\partial \sigma}\right|^{d}=i\left(\mu^{d}, \sigma^{d}\right)\right)$ when evaluated for the same labour supply, i.e.

$$
\left.\frac{\partial \mu}{\partial \sigma}\right|^{S}=\frac{E(\omega)}{[1-\tau] S(\omega)}-\frac{d^{\prime}(h)}{[1-\tau] S(\omega)}>\frac{E(\omega)}{S(\omega)}-\frac{d^{\prime}(h)}{[1-\tau] S(\omega)}=\left.\frac{\partial \mu}{\partial \sigma}\right|^{d}
$$

It follows that $h^{s}>h^{d}$, and hence $\mu^{s}>\mu^{d}$ and $\sigma^{s}>\sigma^{d}$, i.e. the planner chooses a larger labour supply, and therefore both mean income and risk is larger compared to the decentralized outcome.

Note that the difference between the marginal rate of substitution between expected income and risk faced by the social planner and in the decentralized equilibrium is at any point given by

$$
\left.\frac{\partial \mu}{\partial \sigma}\right|^{S}-\left.\frac{\partial \mu}{\partial \sigma}\right|^{d}=\frac{E(\omega)}{S(\omega)}\left[\frac{\tau}{1-\tau}\right] \equiv \varphi>0 \text { for } \tau>0
$$

The wedge $\varphi$ captures the difference between the social optimum and the decentralized allocation for a given tax-transfer scheme.

It is seen that the wedge involves the standard tax distortion $\left(\frac{\tau}{1-\tau}\right)$ but also the ratio of expected wages to their standard deviation $\left(\frac{E(\omega)}{S(\omega)}\right)$. While it is intuitive that this metric is increasing in the tax rate $(\tau)$, it is more interesting that it increasing in the expected value of the shock $(E(\omega))$, but decreasing in the risk $(S(\omega))$. To put it differently, if the factor $\frac{E(\omega)}{S(\omega)}$ is high, the incentive effect is important and the distortionary effect of the tax is amplified, whereas if $\frac{E(\omega)}{S(\omega)}$ is low, the importance of risk, and hence the insurance effect of taxes, is larger, and this tends to reduce the distortionary effect.

The implication is that the wedge $\varphi$ implied by taxes interacts with risk, and therefore deterministic assessments may overestimate the quantitative importance of tax distortions. One may phrase it in the way that the expression above implies that if the wedge is important for the labour supply decision, then it follows that risk is also important. This is seen clearly by considering how risk and the tax rate may be 
substituted to ensure a constant wedge $\varphi$. An implication is that the wedge has an elasticity of minus one with respect to the standard deviation of the shock, while it is $\frac{1}{1-\tau}$ for the tax rate. Hence, for a low initial tax rate, the wedge is numerically (approximately) equally sensitive to risk and to the tax rate (and expected return). Evaluated for a high tax rate, the wedge is numerically more sensitive to the tax rate than to risk. Figure 4 plots the iso-wedge curve in the tax-standard deviation space, and it is seen that the locus is almost linear for moderate tax rates.

Figure 4. Iso-wedge curve: tax and standard deviation of shock.

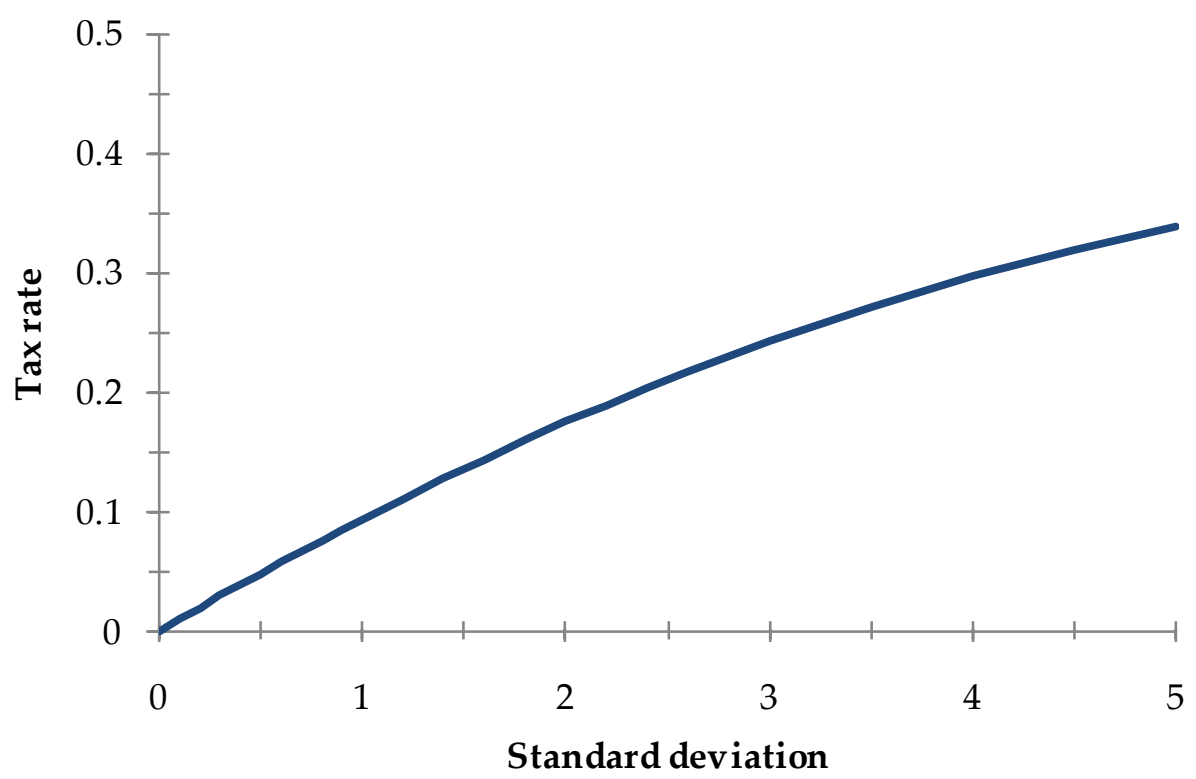

Another way of illustrating the interaction between taxes and risk is seen from the following numerical illustration ${ }^{8}$ showing the labour supply as it depends on the tax rate. The labour supply curves in figure 5 are drawn for different levels of risk. The upper curve is labour supply in the deterministic case, and lower positioned labour supply curves correspond to a higher level of risk (higher $S(\omega)$ ). First, reading vertically, it is seen that for a given tax rate, the larger the risk, the smaller the labour supply is. This is the finding shown analytically above. Second, considering the sensitivity of labour supply to the tax rate, it is seen that the larger the level of risk, the less elastic labour supply is to the tax rate for moderate tax rates (below 50\%). Comparing to the deterministic case, it shows that risk may significantly interact with the standard incentive effects of taxes to make labour supply relatively insensitive to variation in the tax rate over some interval of tax rates. This may be one contributory factor to low estimated tax sensitivities of labour supply, cf. introduction. Finally, note that the lowest positioned labour supply curve has a modest hump-shape; that is, labour supply is initially increasing and then later decreasing in the tax rate, cf. the possibility derived above. However, these

8 The figure is based on the following functional forms: $i(\mu, \sigma)=a+b\left(\frac{\sigma}{\mu}\right)$ (implying constant relative risk aversion), $d(h)=\frac{1}{\gamma} h^{\gamma}$ and the calculations assume: $a=1, b=4, \gamma=4$ (note that the latter assumption implies an elasticity of labour supply in the deterministic case $=0.33$ ). 
numerical illustrations also suggest that such a pattern requires a rather high level of risk (or risk aversion), and therefore the insensitivity of labour supply to taxes is probably more important than the possibility that labour supply may be increasing in the tax rate.

Figure 5. Labour as a function of the tax rate, various levels of risk.

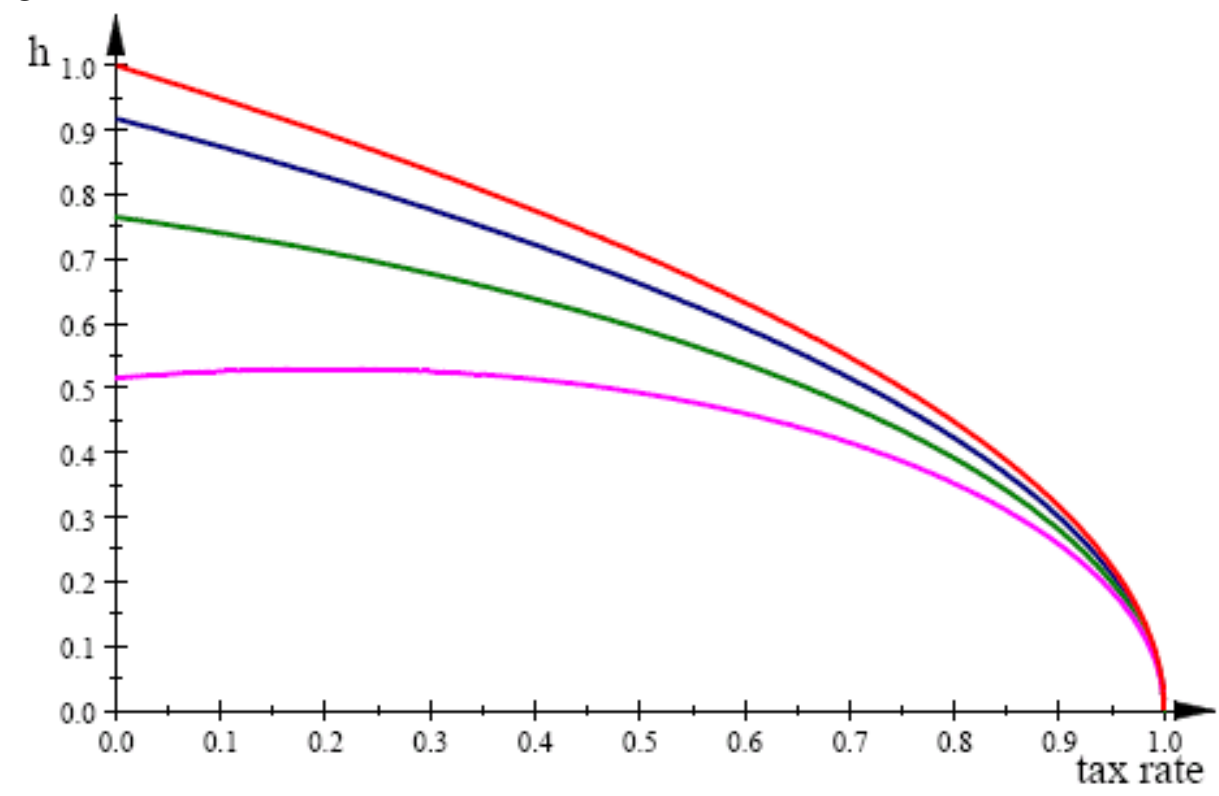

Note: Calculations made for the following values of the standard deviation: $0,0.05,0.1,0.2$, and 0.3 .

\section{Social Optimum - Endogenous Taxes}

The preceding has clarified the choices and distortions arising for a given tax rate in the tax-transfer scheme. Next, we turn to the optimal tax rate under such a scheme. This is done in two steps. First, the opportunity set in the form of the trade-off in the $(\mu, \sigma)$-space is clarified. Next, the optimal policy choice of utilitarian policy makers is considered. The utilitarian assumption carries with it strong implications, but it has the advantage of clarifying some of the considerations going into the determination of tax rates without turning to an explicit modelling of the political process. Note that the model is set up such that risk at the individual level translates to the distributional profile at an economy wide level. Hence, the following explores how the policy makers in their decision on the optimal tax rate balance concerns for incentives and insurance, or equivalently efficiency and equity.

The first thing to work out is the trade-off faced by the policy makers between mean income and distribution. Note that mean of the utility metric here is driven by labour supply, which in turn is affected by the wedge considered above. The distribution profile in utility terms is measured by the standard deviation of the utility metric. Hence, considering the trade-off between the mean and standard deviation of the utility metric gives the trade-off between incentives and insurance, or equivalently between efficiency and equity.

It can be shown that the trade-off may either be monotone as in figure 6.a or humpshaped as in figure 6.b. The monotone trade-off in figure 6.a corresponds to the 
standard case that more equality is associated with more distortionary redistribution, which harms efficiency. The non-monotone relationship is interesting as it points out that up to some point there may not be a conflict between incentives and insurance, but rather they may go hand in hand. The point is that increasing taxes will both reduce inequality and improve efficiency because the insurance offered works to increase labour supply. The hump-shape arises if the underlying risk exceeds some critical level $(S(\theta)>\underline{S})$, which may be interpreted as saying that if risk is sufficiently important, the insurance effect may be so strong as to dominate the incentive effect over some interval. Note that even if we are on the conventionally signed part of figure $6 . \mathrm{b}$ or in figure 6.a, it is still the case that the insurance effect counteracts the incentive effect of taxation, which therefore works to flatten the trade-off (see above on labour supply).

Figure 6. Return-Risk locus.
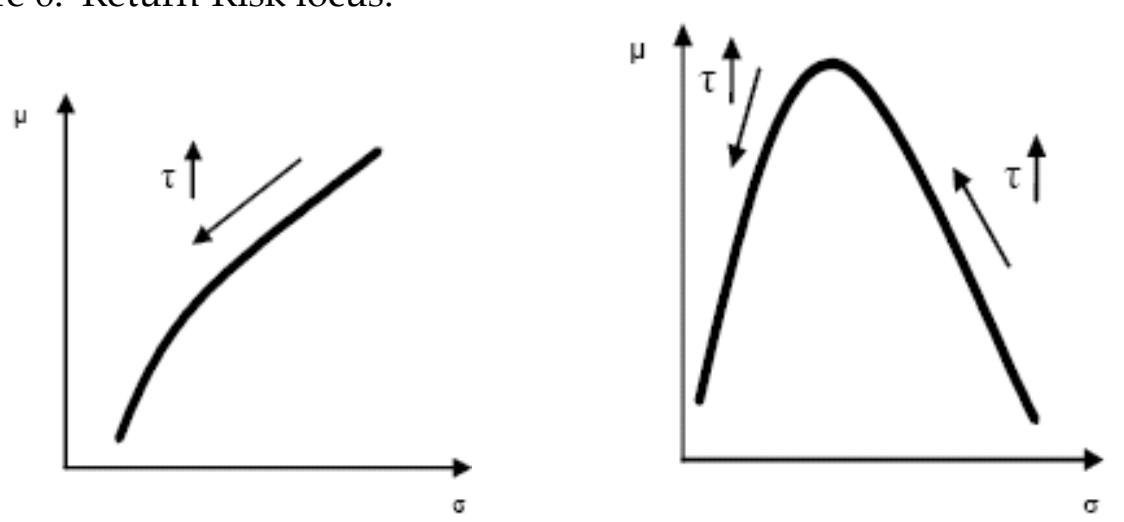

We now consider the optimal choice of the tax rate and therefore the extent of the tax-transfer scheme made by utilitarian policy makers. The optimum is illustrated in figure 7 for the case of a hump-shaped trade-off. It is seen that the optimum is always where there is a conflict or trade-off between efficiency and equity. The intuition for this is straightforward since the government is utilitarian wanting to boost the mean and lower risk, and therefore it would never be optimal to be on the segment where an increase in the tax rate will both increase the mean and lower risk. This finding has one important implication. It is sometimes argued that a concern over the tradeoff between efficiency and equity overlooks that welfare arrangements can also be efficiency enhancing. In the present framework, such efficiency enhancing effects arise via the insurance effect. Yet, the point is that if the policy makers settle on the "right hand side of the hump", it implies that there is an unexploited scope for having both more efficiency and equity, and this situation will of course not be consistent with optimal policy setting. Notice that a consideration of political processes may imply that the political equilibrium implies inefficiencies, i.e. position the economy on the "right hand side of the hump". 
Figure 7. Optimal determination of the tax rate.

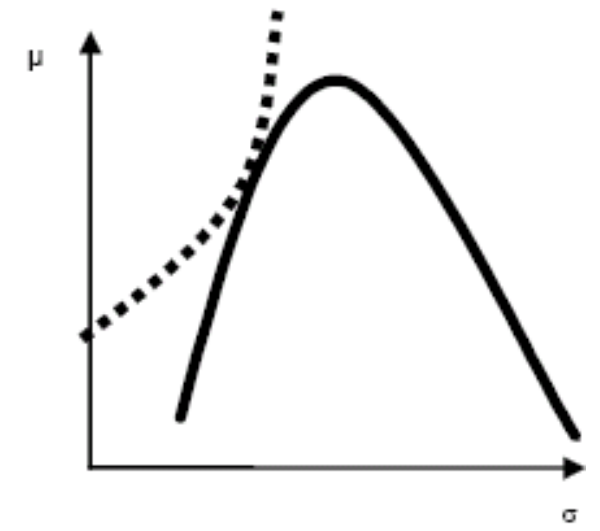

\section{Concluding Remarks}

The trade-off between efficiency and equity captures the most essential policy choice, and therefore it features prominently in the economics literature. However, in a cross-country perspective, there is a significant challenge in explaining the experience of some countries, notably the Scandinavian, which have low income inequality and high tax burdens, and yet high incomes in international comparison. This experience may deny the existence of a steep trade-off. This paper has argued that this is a misreading of the evidence, and that a number of counteracting effects may explain the experience of the Scandinavian countries. One is that welfare policies in general and taxation in particular involve a trade-off between incentives and insurance. The incentive effects are standard, but the insurance effect arises because of the state-contingencies built into welfare arrangements and tax systems. If agents are risk averse, this implicit insurance effect may both have a direct utility effect and an indirect effect on decision making. This has been illustrated for the standard problem of labour supply choices adding wage risk. It was shown that the interaction between taxation and risk raises a number of new aspects that are overlooked in deterministic models. The policy implication of this is that it is important to balance the incentive and insurance effects of given policies, and by so doing it may be possible to achieve both high incomes and egalitarian outcomes. The implication is not that there is not a trade-off for any tax financed activity.

Finally, note that it is still an open question whether the mechanisms explored here can explain the cross-country difference. It is an issue for future research to clarify the difference in income risk across countries in combination with the other "counteracting" factors mentioned in the introduction to fully explain the cross-country evidence presented in figure 1.

\section{References}

Andersen, T.M. (2008). Income taxation: Incentives vs. insurance, Working Paper, Aarhus University.

Andersen, T.M., and R. Dogonowski, (2002). Social Insurance and the Public Budget, Economica, 69, 415-432 
Barr, N. (2001). The Welfare State as a Piggy Bank - Information, Risk, Uncertainty, and the Role of the State, Oxford University Press, Oxford.

Blundell, R.W., and T. MaCurdy (1999). Labour Supply: A Review of Alternative Approaches, in O. Ashenfelter and D. Card (eds.), Handbook of Labour Economics, 34, Elsevier Science, B.V., Amsterdam.

Domar, E.D. and R. Musgrave (1944). Proportional Income Tax and Risk-Taking, Quarterly Journal of Economics, 58, 387-422.

Eaton, J. and H.S. Rosen (1980). Taxation, human capital and uncertainty, American Economic Review, 70, 705-715

Gordon, R.J., (2006). Issues in the Comparison of Welfare Between Europe and the United States, Working Paper presented to Venice Summer Institute, Isola San Servolo, Venice, July 21-23, 2006.

Ljungqvist, L., and T.J. Sargent (2007). Do Taxes Explain European Employment? Indivisible Labour, Human Capital, Lotteries and Savings, CEPR Discussion paper 6196.

Magnusson, G. (1969). Production under Risk - A Theoretical Study, Acta Universitatis Upsaliensis, Studio Oeconomica Upsaliensia 2, Uppsala.

Meyer, J. (1987). Two-Moment Decision Models and Expected Utility Maximization, American Economic Review, 77, 421-430.

Mirrless, J. (1971). An exploration in the theory of optimum income taxation, Review of Economic Studies, 38, 175-208.

Ohanian, L., A. Raffo, and R. Rogerson (2006). Long-term Changes in Labour Supply and Taxes: Evidence from OECD Countries, 1956-2004, NBER Working Paper 12786.

Prescott, E.C. (2004). Why do Americans Work So Much More Than Europeans?, Federal Reserve Bank of Minneapolis, Quarterly Review, 28 (1), 2-13.

Rogerson, R. (2007). Taxation and market work: Is Scandinavia an Outlier?, Economic Theory, 32, 59-85.

Sinn, H.-W. (1995). A Theory of the Welfare State, Scandinavian Journal of Economics, 97, 495-526.

Varian, H. (1980). Progressive taxation as social insurance, Journal of Public Economics, $14,49-68$. 